\title{
"There are no Band-Aids for emotions": The development of thinking about emotional harm
}

\author{
Isobel A. Heck, ${ }^{1}$ Jessica Bregant, ${ }^{2} \&$ Katherine D. Kinzler ${ }^{1 *}$ \\ ${ }^{1}$ University of Chicago, Department of Psychology \\ ${ }^{2}$ Indiana University Maurer School of Law
}

In press at Developmental Psychology

\begin{abstract}
Author Note
Jessica Bregant is now at the University of Houston Law Center, University of Houston. We acknowledge support of NICHD grant R01 HD070890 awarded to Katherine D. Kinzler. We thank Molly Gibian and Kayla Young for help with overseeing data collection and management; Jason Hamm, Ashlyn Smith, and Sasha Diaz for discussion and assistance with data collection; and Paola Ocampo, Kristin Quill, Hanna Swerdin, and Carolyn Todd for help with recruitment. We thank members of the Development of Social Cognition Lab at Cornell University and the University of Chicago for feedback on prior versions of this manuscript. This work was initiated at Cornell University.

Our study design, predictions, and analyses for Experiment 2 were preregistered and are available at: AsPredicted \#12731; https://osf.io/64vha/
\end{abstract}

* Correspondence regarding this article should be addressed to:

Katherine D. Kinzler, Department of Psychology, University of Chicago, 5848 S.

University Ave, Chicago, IL, 60637. kinzler@uchicago.edu. 


\title{
"There are no Band-Aids for emotions": The development of thinking about emotional harm
}

\begin{abstract}
An understanding of harm is central to social and cognitive development, but harm largely has been conceptualized as physical damage or injury. Less research focuses on children's judgments of harm to others' internal well-being (emotional harms). We asked 5-10-year-old children $(N=$ 456, 50\% girls, 50\% boys; primarily tested in Central New York, with socioeconomic diversity, but limited racial/ethnic or linguistic diversity) to compare emotional and physical harms. In Experiment 1, children compared simple harms (intended and completed) and then scenarios in which the perpetrator's intention did not match the outcome (intended emotional harm, but caused physical harm, or vice-versa). Assessments of the severity of emotional (versus physical) harm increased with age and depended on the perpetrator's intentions. In Experiment 2, children saw emotional and physical harms that were: Simple (intended and completed); Incomplete (intended, but not completed); or Accidental (not intended, but completed). Children evaluated physical and emotional harms in isolation and then compared the two. Judgments of the relative severity of emotional harm increased with age, but only when intentions and outcomes were both present. This reflected an increase with age in children's perceptions that emotional harm was hurtful, whereas perceptions of physical harm were relatively stable across development. With age, children also increasingly associated emotional harms with longer-term impacts (being remembered and reoccurring). These findings suggest reasoning about the severity, underlying intentions, and duration of emotional harm shifts with age. The results hold implications for moral development, law and psychology, and emotional-harm-related interventions including those addressing bullying.
\end{abstract}

Keywords: moral development; emotions; social cognition; intentions; law and psychology 


\section{"There are no Band-Aids for emotions": The development of thinking about emotional harm}

Children's understanding of harm has long been at the forefront of the study of social and cognitive development (Kohlberg, 1969; Kohlberg \& Kramer, 1969; Piaget, 1932/1997). In the first years of life, children show a sophisticated understanding of harm: Preschoolers protest and tattle on behalf of those who are harmed (e.g., Vaish, Missana, \& Tomasello, 2011), and infants and preschoolers (e.g., Riedl, Jensen, Call, \& Tomasello, 2015; Vaish, Carpenter, \& Tomasello, 2009, 2010; Van de Vondervoort \& Hamlin, 2017) choose not to help those who have been harmful in the past, even at a cost to themselves (Yudkin, Van Bavel, \& Rhodes, 2019). Across many cultures, children recognize within-group harms as worse than violations of social conventions (Rhodes \& Chalik, 2013; Smetana, 2013; Yau \& Smetana, 2003).

Despite a long history of research on children's reasoning about harm, prior research has most often conceptualized harm as physical in nature (physical damage or injury). With some exceptions, less research has considered children's judgments of harm to others' internal wellbeing (emotional harm; see also “psychological harm”). Existing research suggests even preschoolers judge harming others' emotions to be wrong (Goldstein, Tisak, \& Boxer, 2002; Helwig, Hildebrandt, \& Turiel, 1995; Helwig, Zelazo, \& Wilson, 2001; Smetana, Jambon, \& Ball, 2014; Yoo \& Smetana, 2019), but also that children rate emotional harms as less hurtful than physical harms (Murray-Close, Crick, \& Galotti, 2006; Smetana, Campione-Barr, \& Yell, 2003). Research also provides initial evidence that children's reasoning about emotional and physical harms may differ. For instance, preschoolers' judgments of emotional, but not physical, harms relate to individual differences in empathy (Ball, Smetana, \& Sturge-Apple, 2017).

Many questions remain regarding children's reasoning about emotional harm, and how children's thinking about emotional and physical harm compares and contrasts. In the present 
studies, we examined children's judgments of emotional and physical harm across a wide developmental trajectory. Based on prior research on children's emotional, moral, and social reasoning about harm, we hypothesized that with age, children may increasingly recognize the hurt—which can be potentially long-lasting — caused by emotional injury.

One factor likely to inform children's reasoning about emotional harm is their developing perceptions of others' emotional experiences. For emotional harm, two components of emotion understanding may be particularly relevant: an understanding of self-conscious emotions (those that reflect perceptions of how oneself is viewed in the eyes of others), and an understanding of how emotions extend across time. In the present studies, we focused particularly on emotional harms resulting in embarrassment (i.e., "being made fun of”). An understanding of embarrassment emerges early in life. Children experience embarrassment as early as their second birthday (Lagattuta \& Thompson, 2007), and preschoolers recognize that someone will feel embarrassed directly after an embarrassing event (Bosacki \& Moore, 2004; Chobhthaigh \& Wilson, 2015; Colonnesi, Engelhard, \& Bögels, 2010).

Yet, a deeper understanding of how emotional experiences extend over time develops gradually (Chobhthaigh \& Wilson, 2015; Lagattuta \& Thompson, 2007). Although preschoolers recognize that people with different past experiences may react differently to the same event (Lagattuta \& Wellman, 2001; Pons, Harris, \& de Rosnay, 2004), a mature understanding of how emotional experiences extend over time emerges later (Lagattuta, 2014; Lagattuta \& Sayfan, 2013; Lagattuta, Tashjian, \& Kramer, 2018). In one study, children saw a character experience an embarrassing event and were asked how the character would feel in the same situation the next day. Although 4- to 5-year-olds said the character would feel embarrassed directly following the event, only 7- to 8-year-olds predicted that this emotional experience would extend 
to the next day (Chobhthaigh \& Wilson, 2015). An understanding of how emotions extend over time may be particularly relevant to considerations of emotional injury. Whereas physical pain may fade after the harmful event, emotional pain often endures (see Chen, Williams, Fitness, \& Newton, 2008). We predicted that even young children would judge emotional harm to be wrong, but that a recognition of more complex aspects of emotional injury—particularly regarding the duration of emotional pain-would develop more gradually.

Another factor likely to shape children's thinking about emotional harm is their reasoning about a perpetrator's intentions. Moral judgments are often driven by concerns loosely grouped into two areas: the outcome of an action, and the intentions behind the action. For physical harms, it is well-documented that the relative importance of intentions increases with age. On the one hand, even 8- to 10-month-olds prefer those with helpful intentions to those with harmful intentions (Hamlin, 2013; Woo, Steckler, Le, \& Hamlin, 2017). Likewise, preschoolers protest when accidental moral transgressors - but not intentional transgressors — are punished (Chernyak \& Sobel, 2016), and selectively punish and avoid helping someone who previously displayed harmful intentions, even if that person did not actually complete a harmful outcome (Vaish et al., 2010; Van de Vondervoort \& Hamlin, 2018). Yet, the relative importance of intentions increases over development (Cushman, 2015; Cushman, Sheketoff, Wharton, \& Carey, 2013; Imamoglu, 1975; Nobes, Panagiotaki, \& Pawson, 2009; Proft, Schünemann, \& Rakoczy, 2019; Yuill \& Perner, 1988; Zelazo, Helwig, \& Lau, 1996). Children weigh outcomes relatively more heavily in their moral evaluations than do adults, and younger children tend to weigh outcomes more heavily than do older children (Baird \& Astington, 2005; Cushman, 2015; Cushman et al., 2013; Li \& Tomasello, 2018; Margoni \& Surian, 2017; Nobes et al., 2009; Yuill \& Perner, 1988). Moreover, even when children consider intentions in their moral judgments, this does not 
necessarily mean children are accurate judges of intention; reasoning about the intentions of others is itself a fairly complex cognitive task (Baird \& Astington, 2005; Proft \& Rakoczy, 2019; Wellman, Cross, \& Watson, 2001; Woodward, 2013). For example, children who struggle with false-belief theory of mind tasks are more likely to attribute negative intentions to an accidental harm-doer (Killen, Lynn Mulvey, Richardson, Jampol, \& Woodward, 2011), and younger children may misattribute blame, assuming that a bad outcome results from blameworthy carelessness, even when the outcome was not foreseeable (Cushman et al., 2013; Hamlin, 2013; Killen et al., 2011; Nobes et al., 2009; Woo et al., 2017).

For emotional harms, a consideration of intentions may be especially relevant. When an actor causes physical injury, the outcome (e.g., bruises, cuts, or broken bones) is often visible. For emotional injury, the causal relation between the harmful action and its outcome may be more opaque, making the link between action and outcome potentially less clear than for purely physical injury. We predicted that a perpetrator's intentions may be especially important for children's reasoning about emotional harms, and that reasoning about the relative severity of emotional and physical harm may shift with age, perhaps mirroring a change in children's reasoning about intentions.

Across two experiments, we studied the development of 5- to 10-year-old children's relative judgments of emotional and physical harms, and investigated children's thinking about the associated intentions, outcomes, and perceived duration of these harms. In Experiment 1, we asked children to contrast the severity of emotional and physical harms and began to consider the relative roles of intentions and outcomes in children's reasoning. In Experiment 2 (preregistered: AsPredicted \#12731; https://osf.io/64vha/), we examined the developmental trajectories of children's thinking about emotional harm and presented children with emotional and physical 
harms in which the perpetrators acted in the following ways: intended and completed the harms (Simple harms); intended but failed to complete the harms (Incomplete harms); accidentally completed the harms (Accidental harms). We asked children which harm (emotional or physical) was worse and which harm had longer-lasting impacts.

In addition to children's behavioral choices, we analyzed children's verbal descriptions of the harm events. Research in psycholinguistics suggests a speaker's attentional focus can shape their choice of grammatical subject; the more salient something is, the more likely it is to be the subject of an utterance (Kim, 1996; Myachykov, Garrod, \& Scheepers, 2018; Myachykov, Tomlin, \& Posner, 2005). Indeed, experimentally manipulating people's attentional focus shifts their language (Lempert \& MacWhinney, 1984; Tannenbaum \& Williams, 1968; Tomlin, 1983). In one study, participants were asked to describe an interaction between two people (e.g., an image of one person pushing another) and were cued to focus on the agent (here, the person pushing) or the patient (here, the person being pushed). When focused on the agent, participants more often made the agent the subject of their utterance (e.g., "the agent pushed the patient"); when focused on the patient, participants more often made the patient the subject (often using passive voice; e.g., "the patient was pushed by the agent") (Myachykov et al., 2018; for similar findings with preschoolers, see Lempert \& MacWhinney, 1984). Building on this research, we thought the grammatical construction of children's descriptions of emotional and physical harms may differentially reflect children's focus on the victim (on whom the outcome may be visible) versus perpetrator (who possesses intentions to harm) (see Ferris, Jetten, Hornsey, \& Bastian, 2019 for related discussion). Specifically, if the outcome of physical harm is more salient than the outcome of emotional harm, then children may be more likely to make the victim the grammatical subject when describing the hurt caused by physical versus emotional harms. 


\section{Experiment 1}

We asked 5- to 10-year-old children to directly compare a situation of emotional harm to a situation of physical harm. We selected harms involving purely emotional or physical injury and with which young children were likely to be familiar. For emotional harm, we depicted a scenario in which one character made fun of another character. For physical harm, we depicted a scenario in which one character tripped another character. In the United States, these harms are listed among the most common forms of emotional and physical bullying during childhood, respectively (stopbullying.gov, National Center for Education Statistics and Bureau of Justice). To examine children's thinking about the intentions and outcomes of emotional and physical harms, we next presented children with stories in which the intentions and outcomes of the harms mismatched (i.e., a perpetrator intended physical harm, but accidentally caused emotional harm, and vice versa) and asked children to contrast the two scenarios. We tested how children's comparisons of emotional and physical harm changed with age, and examined the grammatical structure of children's descriptions of the hurt caused by emotional and physical harms.

\section{Methods}

\section{Participants}

Participants were 240 5- to 10 -year-old children $\left(M_{a g e}=8.03\right.$ years; $S D=1.78$ years; 120 girls; 120 boys), with an equal number of children within each age tested. Assuming a medium effect size and $90 \%$ power, power analyses for chi-squared and logistic regression analyses indicated a required minimum sample size ranging from 78-168. Given the importance of increasing sample sizes across psychology and our interest in multiple independent variables, we set our pre-determined total sample size above this limit. We set the lower end of our age range at five - an age at which the majority of children display embarrassment (Buss, Iscoe, \& Buss, 
1979) and recognize others' embarrassment directly following an event (Chobhthaigh \& Wilson, 2015) — and the upper end at 10 — an age at which children demonstrate a more mature understanding of emotional experiences and how they extend over time (Chobhthaigh \& Wilson, 2015; Lagattuta, 2014; Lagattuta \& Sayfan, 2013). Parents of 71\% of children provided demographic information on race/ethnicity. Of those, $71 \%$ identified their children as White, $9 \%$ as mixed race/ethnicity, $8 \%$ as Hispanic or Latinx (21\% of whom also identified as White, $14 \%$ as Black; $7 \%$ as Black and White; $57 \%$ provided no additional information), $6 \%$ as Asian, $3 \%$ as Black, $1 \%$ as Arabic, $1 \%$ as Native American, and $1 \%$ as Other. Parents of $48 \%$ of children reported family income. Of those, income ranged from $<\$ 15,000$ to $>\$ 150,000$, with a median family income of $\$ 75,000$ to $\$ 99,000$. Children were tested in Central New York $(80 \%)$ and Chicago, Illinois (20\%) in a lab, school, or children's museum. Three additional children were tested but excluded due to experimenter error (two) or failure to respond to any questions (one).

\section{Materials}

Children saw four stories, each with two images. Stories were created using Pixton Comics and presented on a laptop. Given differences in gender socialization around harm (e.g., Björkqvist, 1994; Fagot \& Hagan, 1991; Goldstein et al., 2002; Murray-Close et al., 2006), we counterbalanced the gender of the perpetrator (girl or boy) and victim (girl or boy) of the stories. One quarter of the sample (60 children; half girl participants, half boy participants) were assigned to see stories with each of four gender pairings: Boy-Boy, Girl-Girl, Boy-Girl, and GirlBoy. See Supplemental Materials Table S4 for full text from the vignettes.

\section{Procedure}

The procedure was approved by Cornell University's Institutional Review Board (“Development of Social Cognition,” \#1611006763A003). Children heard two stories, one 
depicting a physical harm (i.e., one child trips another child on the playground) and one depicting an emotional harm (i.e., one child makes fun of another child in their classroom), in counterbalanced order (Simple Harm stories). We asked children to indicate which story was worse (Comparing Harms Question 1) and to explain their answer (Explanation Question 1). Next, children compared two similar stories (again in counterbalanced order), but in which the intention and outcome mismatched (either a perpetrator intended emotional harm, but caused physical harm, or intended physical harm, but caused emotional harm) (Mismatched Harm stories). We again asked children to indicate which story was worse (Comparing Harms Question 2) and to explain their answer (Explanation Question 2). Thus, each child answered two Comparing Harms questions and two Explanation questions.

\section{Coding}

For the Comparing Harms questions, we coded whether children selected emotional or physical harm as worse. For the Explanation questions, we coded whether the victim of harm was the subject of the explanation (e.g., "He got hurt"), the object of the explanation (e.g., "Billy hurt him"), both the subject and the object (e.g., "Billy hurt him and he got hurt"), or neither (i.e., no mention of the victim). Two coders - both unaware of participant age and gender - coded children's explanations independently. Initial agreement was 96\% on Explanation Question 1 and $96 \%$ on Explanation Question 2. Disagreements were resolved verbally. Two coders also coded instances in which children mentioned whether or not the harm would fade (e.g., "scrapes will heal; words will haunt you") or stated the time period over which the hurt would last (e.g., "people would remember it for longer"). Initial agreement was $96 \%$ on Explanation Question 1 and $98 \%$ on Explanation Question 2. Disagreements were resolved verbally.

\section{Results}




\section{Comparing Harms Questions 1 and 2}

On Comparing Harms Question 1, 52\% of children chose physical harm as worse and $48 \%$ of children chose emotional harm as worse (not different from chance, $\chi^{2}(1)=0.42, p=$ .519). We constructed a logistic regression model examining the effect of age (in months), victim gender, perpetrator gender, participant gender, and the interactions between victim, perpetrator, and participant gender on children's likelihood of choosing emotional harm as worse (Supplemental Materials Table S1).

There was a significant main effect of age, $\beta=0.02,95 \% \mathrm{CI}[0.01,0.03], S E=0.01$, Wald $\chi^{2}(1)=8.88, p=.003, \mathrm{OR}=1.02$. With age, children were increasingly likely to choose emotional harm as worse than physical harm (Figure 1). There was a significant interaction between perpetrator gender and victim gender, $\beta=1.06,95 \%$ CI [.004, 2.14], SE $=0.54$, Wald $\chi^{2}$ $(1)=3.83, p=.050$. Children chose emotional harm as worse than physical harm most often when the victim and perpetrator were both girls (48\% in Boy-Boy, $41 \%$ in Boy-Girl, $41 \%$ in GirlBoy, and $61 \%$ in Girl-Girl). Additionally, there was a significant interaction between perpetrator gender and participant gender, $\beta=1.35,95 \%$ CI $[0.29,2.43], S E=0.54$, Wald $\chi^{2}(1)=6.16, p=$ .013. Girls chose physical harm as worse more often when the perpetrator was a boy $(67 \%)$ than when the perpetrator was a girl (45\%); in contrast, boys chose physical harm as worse more often when the perpetrator was a girl (53\%) than when the perpetrator was a boy $(43 \%)$.

\section{Figure 1}

Children's responses to Comparing Harms Questions 1 and 2 by participant age 

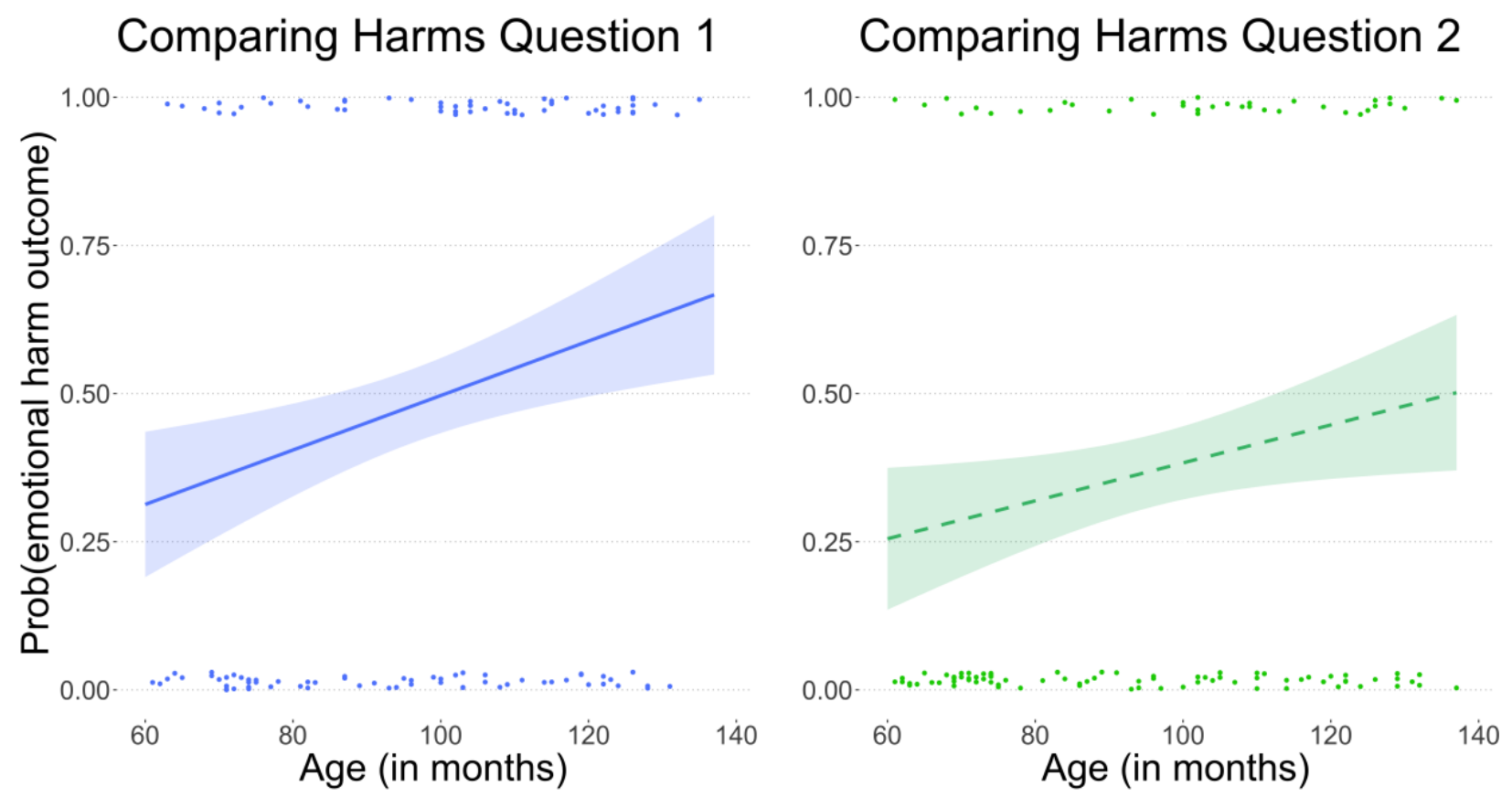

Note. Probability of children choosing stories with an emotional harm outcome as worse on Comparing Harms Question 1 (left; purple, solid) and Comparing Harms Question 2 (right; green, dashed) across participant age. Shaded areas represent 95\% Confidence Intervals.

On Comparing Harms Question 2, 63\% of children chose the emotional intention/physical outcome story as worse and $37 \%$ chose the physical intention/emotional outcome story as worse (significantly different from chance, $\chi^{2}(1)=16.02, p<.001$ ). We constructed a logistic regression model with participants' likelihood of choosing the physical intention/emotional outcome story as the outcome and age (in months), perpetrator gender, victim gender, participant gender, and the interactions between perpetrator, victim, and participant gender as predictors (see Supplemental Materials Table S2). There was a main effect of age, $\beta=0.01,95 \%$ CI [0.001, 0.03], $S E=0.01$, Wald $\chi^{2}(1)=4.43, p=.035, O R=1.01$. With age, children were increasingly likely to select the physical intention/emotional outcome story as worse than the emotional intention/physical outcome story (Figure 1). There was an interaction between perpetrator and victim gender, but this finding did not reach statistical significance, $\beta=$ $1.05,95 \%$ CI $[-0.04,2.15], S E=0.56$, Wald $\chi^{2}(1)=3.56, p=.059$. Children chose the physical 
intention/emotional outcome story as worse most often when both the victim and the perpetrator were girls (38\% in Boy-Boy, $27 \%$ in Boy-Girl, 31\% in Girl-Boy, and $49 \%$ in Girl-Girl). There was also an interaction between participant gender and perpetrator gender, $\beta=1.07,95 \% \mathrm{CI}[-$ $0.02,2.16], S E=0.56$, Wald $\chi^{2}(1)=3.68, p=.055$. Girl participants were more likely to choose the emotional intention/physical outcome story as worse when the perpetrator was a boy (72\%) than when the perpetrator was a girl (53\%). In contrast, boy participants' responses depended less on perpetrator gender (boy perpetrator: 60\%; girl perpetrator: 67\%).

Responses to the two Comparing Harms questions were related, $\chi^{2}(1)=11.82, p<.001$. Children who chose physical harm on Comparing Harms Question 1 were more likely to select the emotional intention/physical outcome story (vs. the physical intention/emotional outcome story) as worse on Comparing Harms Question 2 (74\%, greater than chance, $\chi^{2}(1)=27.85, p<$ .001). In contrast, children who chose emotional harm as worse on Comparing Harms Question 1 were equally likely to choose the emotional intention/physical outcome story (51\%) and the physical intention/emotional outcome story (49\%) on Comparing Harms Question 2 (not different from chance, $\left.\chi^{2}(1)=0.08, p=.780\right)$.

\section{Explanations}

On Explanation Question 1, eight children (3\%) did not provide responses (e.g., "I don’t know), so were excluded from analyses. Explanations of emotional and physical harms differed in their grammatical placement of the victim, $\chi^{2}(3, N=232)=52.84, p<.001$. Children who described why physical harm was worse were most likely to make the victim the subject. In contrast, children who explained why emotional harm was worse were more likely to make the victim the object or not to mention the victim at all (Table 1). On Explanation Question 2, children's explanations similarly depended on the outcome of the harm described, Fisher's Exact 
Test $p<.001$. Children describing the hurt caused by the emotional intention/physical outcome story were most likely to make the victim the grammatical subject; children who described the hurt caused by the physical intention/emotional outcome story were most likely to make the victim the grammatical object of the explanation, or not to mention the victim at all.

\section{Table 1}

Explanation Questions 1 and 2 by children's choice on the associated Comparing Harms Question

\begin{tabular}{|c|c|c|c|c|c|}
\hline & & \multicolumn{2}{|c|}{ Explanation Ouestion 1} & \multicolumn{2}{|c|}{ Explanation Question 2} \\
\hline & & $\begin{array}{r}\text { Response to } \\
Q \\
\end{array}$ & aring Harms & $\begin{array}{r}\text { Response to } \\
Q u \epsilon \\
\end{array}$ & $\begin{array}{l}\text { nparing Harm } \\
\text { on } 2\end{array}$ \\
\hline Reference & Example & $\begin{array}{c}\text { PH } \\
(N=125)\end{array}$ & $\begin{array}{c}\text { EH } \\
(N=115)\end{array}$ & $\begin{array}{c}\text { EH intention } \\
\text { PH outcome } \\
(\mathrm{n}=151) \\
\end{array}$ & $\begin{array}{c}\text { PH intention } \\
\text { EH outcome } \\
(\mathbf{n}=89) \\
\end{array}$ \\
\hline Subject & "She might get hurt." & $45 \%$ & $11 \%$ & $45 \%$ & $11 \%$ \\
\hline Object & "She hurt the person." & $30 \%$ & $46 \%$ & $30 \%$ & $46 \%$ \\
\hline Both & $\begin{array}{l}\text { "She teased someone. He } \\
\text { might have been } \\
\text { embarrassed." }\end{array}$ & $8 \%$ & $7 \%$ & $8 \%$ & $7 \%$ \\
\hline Neither & $\begin{array}{l}\text { "Really mean in front of a } \\
\text { lot of people." }\end{array}$ & $16 \%$ & $36 \%$ & $16 \%$ & $36 \%$ \\
\hline
\end{tabular}

Note. Examples of children's explanations (victim mentions bolded). The percentage of children referring to the victim as the subject, object, both, or neither, by response to the associated Comparing Harms Question (Explanation Question 1: Physical or Emotional Harm; Explanation Question 2: Emotional intention/Physical outcome or Physical intention/Emotional outcome).

On Explanation Question 1, 22 children spontaneously mentioned the duration of harm.

Of those, the majority of children were describing the hurt caused by emotional harm $(n=18)$. Indeed, children were significantly more likely to mention the duration of harm when describing the hurt caused by emotional (vs. physical) harm, $\chi^{2}(1, N=22)=8.91, p=.003$. Given that spontaneous mentions of harm duration were relatively rare, we were limited in the analyses we could conduct with respect to age. However, the majority of these references to duration were generated by children over age 8 ( $73 \%$ provided by children age 8 and older). Children were less likely to mention the duration of harm on Explanation Question 2; only seven children did so, 
and these instances were split across story types ( $n=3$ emotional intention/physical outcome; $n$ $=4$ physical intention/emotional outcome).

\section{Discussion}

Children's judgments of emotional harm—in relation to their judgments of physical harm—changed across ages 5 to 10 . With age, children were increasingly likely to choose emotional harm as more severe than physical harm. The results also provide preliminary evidence that children may be relatively more attuned to the outcome of physical harm and the intentions underlying emotional harm. When we presented scenarios in which the perpetrator's intention mismatched the outcome, children who said physical harm was worse on the first Comparing Harms question tended to choose the mismatched intention-outcome scenario with a physical harm outcome. In contrast, children who said emotional harm was worse on the first Comparing Harms question were equally likely to choose mismatched intention-outcome stories featuring emotional harm as the intention or the outcome. The structure of children's explanations complemented this pattern. Children who described the hurt caused by physical harm tended to make the victim the grammatical subject of their explanation, whereas children who described the hurt caused by emotional harm were less likely to mention the victim at all. When they did, these children more often made the victim the grammatical object, often focusing instead on the perpetrator. This grammatical pattern may reflect a difference in children's attentional focus: When thinking about physical harms, children may focus more on the victim, on whom the outcome of harm is visible; when thinking about emotional harms, children may focus more on the perpetrator, who possesses the intentions underlying the harm.

We saw some evidence that the gender of the perpetrator and victim mattered. Children were most likely to choose emotional harm as worse than physical harm when the victim and 
perpetrator were both girls. This finding parallels past research suggesting parents and teachers more often socialize boys to engage in physical harms and girls to engage in relational harms (e.g., teasing, exclusion, rumor spreading) (e.g., Björkqvist, 1994; Fagot \& Hagan, 1991; Goldstein et al., 2002). Such differing messages can form gendered expectations about the kinds of harm in which others are likely to engage. For example, children in past research expected girls to engage in harms like rumor spreading and expected boys to engage in physical harms like hitting (Crick, Bigbee, \& Howes, 1996; Crick \& Werner, 1998; Giles \& Heyman, 2005; Tisak, Tisak, \& Goldstein, 2001). The present results suggest stereotypic associations between gender and harm may influence children's judgments of harm events.

In sum, Experiment 1 suggests children's comparative judgments of emotional and physical harms shift over early childhood, and provides initial evidence that a perpetrator's intentions may be especially salient in children's reasoning about emotional harm. In Experiment 2, we built on these findings and addressed two important limitations. First, although Experiment 1 illustrates a shift in children's reasoning about the relative severity of emotional and physical harms, the direction of this change is unclear. The observed pattern may reflect a change in children's thinking about physical harm; with age, children may view physical harm as less hurtful. Alternatively, children's thinking about emotional harm may change; with age, children may view emotional harm as more hurtful. Or, both may be true; with age, children may view physical harm as less hurtful, and view emotional harm as more hurtful. In Experiment 2, we first asked children to consider emotional and physical harms in isolation. Second, the mismatched intention-outcome stories in Experiment 1 required children to simultaneously reason about these harms' intentions and outcomes. In Experiment 2, we compared simple harms to cases in which only the harmful intention or only the harmful outcome is present. 


\section{Experiment 2}

In Experiment 2, we compared "Simple" emotional and physical harms (i.e., the harm was intended and completed) to harms in which the perpetrator's harmful intentions were present, but not the outcome ("Incomplete harms"), and harms in which the harmful outcome is present, but not the perpetrator's intentions ("Accidental harms"). Children evaluated emotional and physical harms in isolation and then compared the severity of the two. We again asked children to explain their choice and examined the grammatical structure of these explanations.

We predicted children would rate emotional harm as increasingly hurtful with age. Second, we predicted intentions would matter more for emotional harm than for physical harm. Thus, we expected emotional harm would be seen as more severe when it was incomplete (intended, but not completed) than when it was accidental (not intended, but completed). In Experiment 1, children were more likely to spontaneously mention the duration of emotional harm compared to the duration of physical harm. In Experiment 2, we expressly tested children's reasoning about the longer-term impacts of harm by asking children which victim (that of emotional or physical harm) would be more likely to remember the event, and which event (emotional or physical harm) would be more likely to reoccur two weeks later.

\section{Method}

\section{Participants}

Participants were 2165 - to 10 -year-old children $\left(M_{\text {age }}=7.94\right.$ years; $S D=1.69 ; 108$ girls; 108 boys), with an equal number of children within each age tested. We again set our predetermined sample size above minimums determined by sample size calculations, and based on all relevant counterbalancing factors. Parents of $64 \%$ of children provided demographic information. Of those, $73 \%$ identified their children as White, $8 \%$ as Other, $6 \%$ as mixed 
race/ethnicity, 5\% as Asian, 4\% as Hispanic or Latinx, 2\% as Black, and 2\% as Native Hawaiian American. Parents of $56 \%$ of children reported family income. Of those, family income ranged from $<\$ 15,000$ to $>\$ 150,000$ with a median reported family income of $\$ 75,000$ to $\$ 99,000$. Children were tested in Central New York in a lab, school, or children's museum. Children were randomly assigned to one of three between-subjects conditions ( $n=72$ per condition): Simple harm, in which the perpetrator intends to harm the victim and ultimately completes this harm; Incomplete harm in which the perpetrator intends to harm the victim but fails to complete this harm; and Accidental harm, in which the perpetrator does not intend to harm the victim, but accidentally does so. Given the gender effect observed in Experiment 1, we counterbalanced across conditions and participant gender whether children saw scenarios involving two boys or two girls.

\section{Materials}

We created new stories using Pixton Comics. Additional materials included a piece of paper depicting three circles, arranged laterally and increasing in size from left to right.

\section{Procedure}

The procedure was approved by Cornell University's Institutional Review Board (“Development of Social Cognition, \#1611006763A003) and was preregistered (AsPredicted \#12731; https://osf.io/64vha/). Within each condition, participants heard two stories—one about an emotional harm and one about a physical harm — in counterbalanced order. We designed the vignettes to equate the emotional and physical harm scenarios, and language used to describe them, as closely as possible. Specifically, we considered the potential impacts of an audience being present and the degree of physical contact between the perpetrator and the victim. To equate the presence or absence of an audience, we removed the classmates from the scenes in the 
emotional harm stories. To equate for the degree of physical contact between victim and perpetrator, the perpetrator in both stories sets up a scenario that leads to the victim's harm, but the perpetrator is not present when the harm takes place. Specifically, the perpetrator tells the victim that the next day at school is "swing day" (physical harm) or "costume day" (emotional harm). This information will lead to the victim being physically harmed (tripped) or emotionally harmed (made fun of). The perpetrator either knows this (Simple harm and Incomplete harm) or does not know this (Accidental harm). The following day, the victim either remembers or forgets what the perpetrator said (that it is swing/costume day), such that the victim is harmed (Simple harm and Accidental harm) or left unscathed (Incomplete harm) (see Supplemental Materials Table S5 for images and full text).

After each story (emotional harm, physical harm), we asked children to explain what happened (Recall Question). Next, we asked children four Scale Questions regarding how hurtful, mean, worthy of punishment, and intentional they perceived the depicted action to be. For each, we first asked children yes-or-no questions (e.g., "Did the perpetrator hurt the victim?"). If children responded "no," the experimenter proceeded to the following question. If children responded "yes," they were asked to quantify their response using three circles increasing in size from left to right and verbally labeled "a little," "a medium amount," and "a lot." After children answered these questions for each story, we showed them a single image from each story simultaneously and asked them to indicate which story was worse (Comparing Harms Question) and to explain their answer (Explanation Question). On two final questions, we asked children to compare the longer-term impacts of the emotional and physical harms: which victim will be more likely to remember the event (Remember Question) and which event is more likely to reoccur two weeks later (Reoccur Question). 


\section{Coding}

We coded how hurtful, mean, worthy of punishment, and intentional children rated the harms on a 0-3 scale ranging from "not at all" (0) to "a lot" (3). For the Explanation Question, we again coded the grammatical nature of children's references to the victim as the subject, object, both, or neither, and we preregistered this coding scheme (AsPredicted \#12731; https://osf.io/64vha/). Two coders-both unaware of participant age and gender-coded children's explanations. Initial agreement was $97 \%$ and disagreements were resolved verbally.

\section{Results}

\section{Recall Question}

When asked what happened in the stories, $94 \%$ of children provided responses for both stories. All of these responses were accurate, suggesting children understood the stories. Of the 13 children who did not respond to both questions, one could not remember what happened in the emotional harm story $\left(M_{a g e}=5.48\right)$, four could not remember what happened in the physical harm story $\left(M_{a g e}=7.16\right)$, and seven did not respond to either Recall Question (Mage $\left.=5.89\right)$.

These instances were evenly distributed across conditions and excluding these participants from analyses does not change the results presented below.

\section{Scale Questions}

For each rating (eight total), we constructed a generalized linear model with rating as the outcome and condition, age (in months), participant gender, and stimuli gender as predictors (additionally considering interactions between these factors). On children's ratings of the hurt caused (one for emotional harm, one for physical harm), there were main effects of condition (EH: Wald $\chi^{2}(2)=35.74, p<.001$; PH: Wald $\chi^{2}(2)=47.26, p<.001$; see Table 2). Children's ratings of emotional, but not physical, harm changed with age. With age, children rated 
emotional harm as increasingly hurtful, $\left(\beta=0.01,95 \%\right.$ CI $[0.003,0.02], S E=0.004$, Wald $\chi^{2}(1)$ $=6.78, p=.009, O R=1.011)$. In contrast, children's ratings of the hurt caused by physical harm did not change with age, $\beta=-0.002,95 \%$ CI [-0.01, 0.01], $S E=0.004$, Wald $\chi^{2}(1)=0.18, p=$ $.667, O R=0.998($ Figure 2$)$.

\section{Figure 2}

Children's ratings of the hurt caused by Emotional and Physical Harm by participant age

Emotional Harm 3.

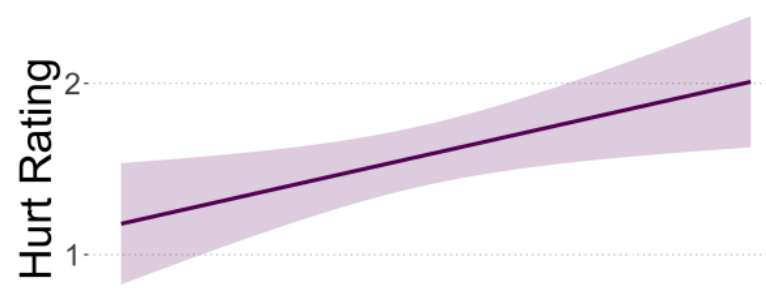

0 60 ${ }^{80}$ Age (in months) ${ }^{120}$

\section{Physical Harm}

3.

2

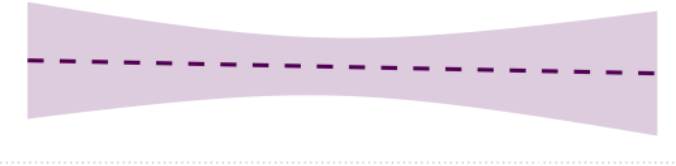

1 -

${ }^{80}$ Age (in months) ${ }^{120}$

Note. Children's ratings of how hurtful the emotional harm (left; solid) and physical harm (right; dashed) were across age (in months). Higher values indicate greater perceptions of hurt caused. Shaded areas represent $95 \%$ Confidence Intervals.

Children's ratings of how mean the harms were also varied by condition (EH: Wald $\chi^{2}(2)$ $=100.13, p<.001$; PH: Wald $\left.\chi^{2}(2)=93.15, p<.001\right)$, but did not change with age $(\mathrm{EH}: p=$ .165 ; PH: $p=.634)$. On children's ratings of how much the harms should be punished, there were significant interactions between condition and age $\left(\mathrm{EH}\right.$ age* condition: Wald $\chi^{2}(2)=6.51, p$ $=.039 ; \mathrm{PH}$ age $*$ condition: Wald $\left.\chi^{2}(2)=6.76, p=.034\right)$. With age, children rated the Simple Harms as increasingly deserving of punishment and the Accidental Harms as decreasingly deserving of punishment. On children's ratings of how intentional the harms were, there were also interactions between condition and age, though this interaction was only significant for the 
emotional harm ratings (EH: age*condition, Wald $\chi^{2}(2)=7.36, p=.025 ; \mathrm{PH}$ : age*condition,

Wald $\left.\chi^{2}(2)=4.59, p=.10\right)$. With age, children rated the harms as increasingly intentional (EH: $\beta$ $=0.02,95 \%$ CI $[0.003,0.03], S E=0.006$, Wald $\chi^{2}(1)=6.46, p=.011, O R=0.998 ; \mathrm{PH}: \beta=$ $0.01,95 \%$ CI $[0.006,0.02], S E=0.003$, Wald $\left.\chi^{2}(1)=15.94, p<.001, O R=1.01\right)$, and this was particularly the case when the harms were in fact intended (Simple Harm and Incomplete Harm).

See Table 2 for average responses to the Scale Questions within each condition and harm type (emotional versus physical).

Table 2

Mean responses to the Scale Questions within each condition and harm type

\begin{tabular}{|c|c|c|c|}
\hline Scale Question & Condition & Emotional Harm & Physical Harm \\
\hline \multirow{3}{*}{ Hurt } & Simple & 2.21 & 2.18 \\
\hline & Incomplete & 0.97 & 0.88 \\
\hline & Accidental & 1.54 & 1.63 \\
\hline \multirow{3}{*}{ Mean } & Simple & 2.46 & 2.45 \\
\hline & Incomplete & 2.17 & 2.25 \\
\hline & Accidental & 0.90 & 0.93 \\
\hline \multirow{3}{*}{ Punishment* } & Simple & 1.92 & 1.88 \\
\hline & Incomplete & 1.46 & 1.63 \\
\hline & Accidental & 0.58 & 0.63 \\
\hline \multirow{3}{*}{ Intentionality* } & Simple & 1.88 & 1.97 \\
\hline & Incomplete & 1.72 & 1.92 \\
\hline & Accidental & 0.10 & 0.08 \\
\hline
\end{tabular}

Note. Average response across participants to each of the four Scale Questions (hurt, mean, punishment, and intentionality) by condition (Simple, Incomplete, Accidental; between-subjects) and harm type (emotional harm, physical harm; within-subjects). *Note that the means for children's punishment and intentionality ratings should be considered with respect to interactions between condition and age.

There was an unpredicted interaction between stimuli gender and participant age on ratings of how much emotional harm should be punished $\left(\mathrm{EH}\right.$ : age*stimuli gender, Wald $\chi^{2}(2)=$ $6.77, p=.009)$. Children rated emotional harm as more worthy of punishment when the actors were girls versus boys and this difference widened with age. There were no other effects of participant gender (all $p$ 's $>.20$ ) nor stimuli gender (all $p$ 's $>.22$ ) on children's ratings. 
To further examine children's relative ratings of the two harms, we computed difference scores between ratings of emotional and physical harm (EH rating $-\mathrm{PH}$ rating; range: -3 to +3 ). For each difference score (four total), we constructed a generalized linear model with difference score as the outcome and condition, age, participant gender, and stimuli gender as predictors (additionally considering interactions between these factors). With age, children were increasingly likely to rate emotional harm as more hurtful than physical harm, $\beta=0.01,95 \% \mathrm{CI}$ [0.004, 0.02], $S E=0.004$, Wald $\chi^{2}(1)=9.39, p=.002, O R=1.01$. No other effects were significant.

\section{Comparing Harms Question}

Overall, $74 \%$ of children chose physical harm as worse and $26 \%$ chose emotional harm as worse (significantly different from chance, $\chi^{2}(1)=41.98, p<.001$ ). We constructed a logistic regression model with children's likelihood of choosing the emotional harm story as worse and age (in months), condition, participant gender, and stimuli gender as predictors (additionally considering interactions between these factors) (Supplemental Materials Table S3). There was a significant interaction between age and condition, Wald $\chi^{2}(2)=8.91, p=.010$. When harms were intended and completed (Simple harms), children's likelihood of choosing emotional harm as more severe than physical harm increased with age, $\beta=0.05,95 \%$ CI $[0.02,0.09], S E=.02$, Wald $\chi^{2}(1)=10.35, p=.001, O R=1.05$. In contrast, judgments of accidental and incomplete emotional versus physical harms did not change with age $(p=.100, p=.537$, respectively). Thus, the difference we predicted with respect to children's reasoning about incomplete versus accidental harms was present among younger children, but not older children. Younger children chose emotional harm as worse most often when harms were Incomplete, and least often when harms were Accidental. In contrast, older children chose emotional harm as worse most often 
when harms were Simple and were equally likely to choose emotional harm as worse when harms were Incomplete and Accidental. There were no effects of stimuli gender (Boy-Boy: $25 \%$ emotional harm; Girl-Girl: 31\% emotional harm; $\beta=-0.33, p=.30$ ) or participant gender (boy participants: $29 \%$ emotional harm; girl participants: $27 \%$ emotional harm; $\beta=0.13, p=.69$ ).

Children's responses to the Comparing Harms Question related to their ratings on the Scale Questions. The more hurtful, mean, worthy of punishment, and intentional children rated emotional harm compared to physical harm, the more likely they were to choose emotional harm as worse than physical harm $\left(H u r t: \beta=0.46,95 \%\right.$ CI $[0.17,0.78], S E=.15$, Wald $\chi^{2}(1)=8.99, p$ $=.003, O R=1.58 ;$ Mean $: \beta=0.736,95 \%$ CI $[0.38,1.14], S E=.19$, Wald $\chi^{2}(1)=14.70, p<.001$, OR $=2.09 ;$ Punish: $\beta=0.55,95 \%$ CI $[0.19,0.96], S E=.19$, Wald $\chi^{2}(1)=8.249, p=.004, O R=$ 1.74; Intend: $\beta=0.38,95 \%$ CI [0.008, 0.70], $S E=.17$, Wald $\left.\chi^{2}(1)=8.99, p=.05, O R=1.40\right)$.

\section{Remember Question}

We constructed a logistic regression model with response to the Remember Question as the outcome and age (in months), condition, participant gender, and stimuli gender as predictors (additionally considering interactions between these variables). There was a main effect of age and no effects of condition, participant gender, or stimuli gender. Older children were more likely than younger children to choose the victim of emotional harm (vs. physical harm) as more likely to remember the incident, $\beta=0.03,95 \%$ CI $[0.02,0.05], S E=.01$, Wald $\chi^{2}(1)=20.08, p<$ $.001, O R=1.03$ (Figure 3). Further, controlling for age, responses to the Remember Question related positively to responses to the Comparing Harms Question, $\beta=0.74,95 \%$ CI $[0.09,1.40]$, $S E=0.33$, Wald $\chi^{2}(1)=4.82, p=.03, O R=2.09$.

\section{Figure 3}

Responses to the Remember and Reoccur Questions by participant age 
Remember

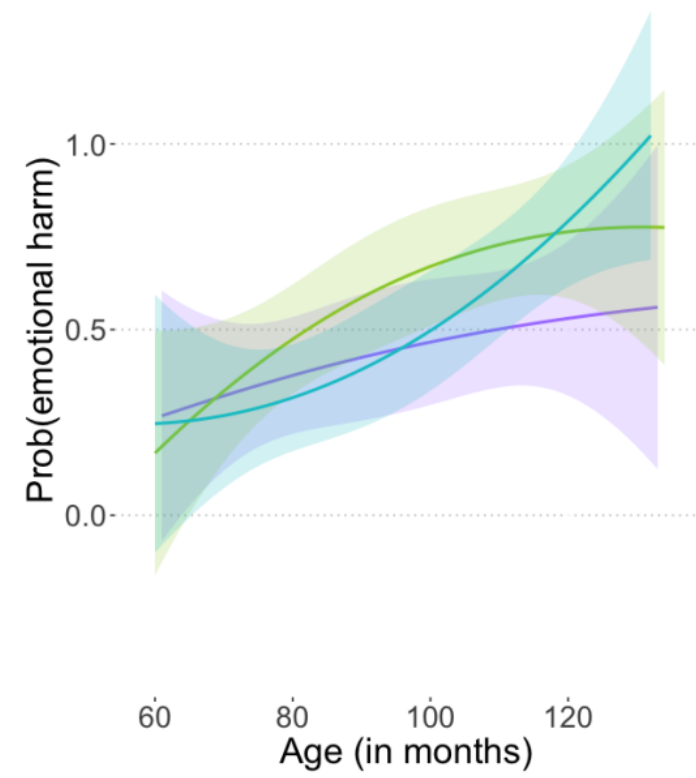

Reoccur

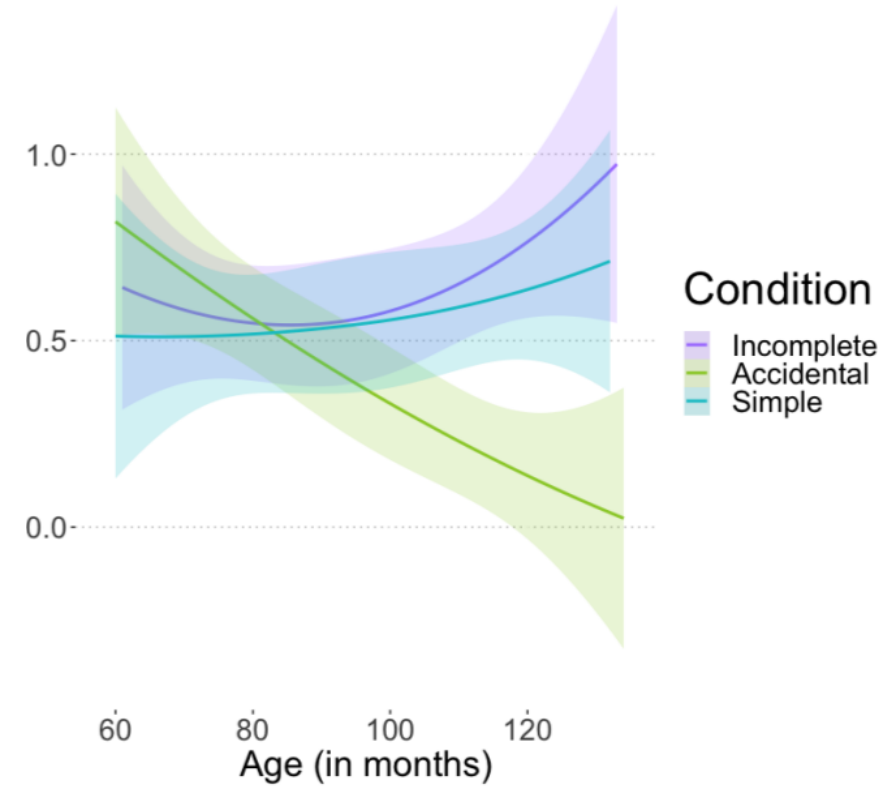

Note. The probability of children choosing the emotional harm story as more likely to be remembered by the victim (left) and more likely to reoccur two weeks later (right) across age (in months) and condition. Shaded areas represent 95\% Confidence Intervals.

\section{Reoccur Question}

We constructed a logistic regression model with response to the Reoccur Question as the outcome and age (in months), condition, participant gender, and stimuli gender as predictors. There were no effects of participant or stimuli gender. The interaction between age (in months) and condition explained additional variance, likelihood ratio test, $\chi^{2}(2)=17.53, p<.001$ (Figure 3). Among younger children, there was little difference between conditions in which harm children thought would reoccur. However, with age, children's responses increasingly depended on whether the harm was intended. Children more often chose emotional harm as likely to reoccur when the harm was intended (Incomplete and Simple), but more often chose physical harm as likely to reoccur when the harm was not intended (Accidental). Responses to the Reoccur Question did not relate to responses to the Comparing Harms Question, $p=.48$.

\section{Explanations}


Six children (three in Simple Harm, one in Accidental Harm, and two in Incomplete Harm) provided no response (e.g., "I don't know"). The structure of children's explanations differed by harm described, Fisher's Exact Test $p<.001$ (Table 3). When describing the hurt caused by physical harm, children most often referred to the victim as the subject. When describing the hurt caused by emotional harm, children were equally likely to refer to the victim as the subject and object (Table 3). The structure of children's explanations also differed by condition, Fisher's Exact Test, $p=.048$, and this pattern was present among children who described emotional and physical harms. Children were most likely to refer to the victim as the subject when harms were accidental (72\%), and comparatively less likely to refer to the victim as the subject when harms were incomplete (53\%) or both intended and completed (59\%) (Table 3).

Table 3

Explanation Question by response to the Comparing Harms Question and condition

\begin{tabular}{|c|c|c|c|c|c|c|}
\hline \multirow[b]{2}{*}{ Reference } & \multirow[b]{2}{*}{ Example } & \multicolumn{2}{|c|}{$\begin{array}{c}\text { Response to Comparing } \\
\text { Harms Question }\end{array}$} & \multicolumn{3}{|c|}{ Condition } \\
\hline & & $\begin{array}{c}\text { PH } \\
(N=125)\end{array}$ & $\begin{array}{c}\text { EH } \\
(N=115)\end{array}$ & $\begin{array}{c}\text { Simple } \\
(N=72)\end{array}$ & $\begin{array}{c}\text { Accidental } \\
(N=72)\end{array}$ & $\begin{array}{c}\text { Incomplete } \\
(N=72)\end{array}$ \\
\hline Subject & "She got hurt." & $72 \%$ & $36 \%$ & $59 \%$ & $72 \%$ & $53 \%$ \\
\hline Object & $\begin{array}{l}\text { "Someone was trying } \\
\text { to hurt her." }\end{array}$ & $12 \%$ & $34 \%$ & $19 \%$ & $8 \%$ & $27 \%$ \\
\hline Both & $\begin{array}{l}\text { "He was warning him, } \\
\text { but he got made fun } \\
\text { of." }\end{array}$ & $3 \%$ & $4 \%$ & $2 \%$ & $1 \%$ & $1 \%$ \\
\hline Neither & $\begin{array}{l}\text { "There might be } \\
\text { blood." }\end{array}$ & $16 \%$ & $26 \%$ & $20 \%$ & $18 \%$ & $19 \%$ \\
\hline
\end{tabular}

Note. Examples of children's explanations (victim mentions bolded) and the percentage of children referring to the victim as the subject, object, both, or neither, by response to the Comparing Harms Question and condition.

\section{Discussion}

Children's judgments of the hurt caused by emotional harm, but not physical harm, changed with age. Across ages 5 to 10, children rated emotional harm as increasingly hurtful. In 
contrast, ratings of physical harm were more consistent. We also saw a shift in children's thinking about the lasting impacts of emotional harm. The older children were, the more likely they were to associate a longer-lasting memory of the event with emotional versus physical harm. Controlling for age, children who said emotional harm was more likely to be remembered were also more likely to say emotional harm was worse.

The present results raise questions about the relation between children's temporal cognition and judgments of emotional harm. One possibility is that the youngest children in our sample struggled to reason about the duration of harm at all. This seems unlikely given evidence that children can by age 5 anticipate future events (Atance, 2015) and accurately report that “today” precedes “next week," which precedes “next year” (Tillman, Marghetis, Barner, \& Srinivasan, 2017). At the same time, children's temporal cognition (e.g., Atance, 2015; McCormack, 2015; McCormack \& Hoerl, 2017; Tillman et al., 2017) and experiences of related emotional experiences (e.g., "regret"; McCormack, Feeney, \& Beck, 2020) continue to develop over early childhood, and these developments may underlie shifts in children's thinking about emotional injury. An interesting related question is whether duration of harm may be more important to some children's reasoning than others'. In the present study, children were more likely to associate emotional harm with longer-term impacts than they were to choose emotional harm as worse than physical harm. One possibility is that duration of pain is a particularly defining aspect of emotional harm, but that individual children's judgments of emotional harm are influenced by duration to varying degrees. A complementary possibility is that the Comparing Harms question ("Which is worse?") led children to think about the moments directly following the incident, but that children's responses to this question may differ if asked to think specifically about a point later in time. 
We saw further support that intentions and outcomes may differentially contribute to children's reasoning about emotional and physical harms. Children more often referred to the victim as the subject when describing physical harms and accidental harms. This finding provides converging support for the idea that children's attentional focus is more likely to be on the victim when the perpetrator's intentions are less salient. Children's predictions of which harm was more likely to reoccur also depended on the presence versus absence of intentions: The older children were, the more likely they were to choose emotional harm as more likely to reoccur, but only when the harm was intended. The tendency we predicted for children to choose emotional harm more often when the harm was incomplete versus accidental was present in younger children's reasoning, but not older children's reasoning. One possibility is that incomplete emotional and physical harms are actually quite similar (someone intends harm, and there is no discernable outcome), and that older children picked up on this. In contrast, younger children's reasoning about physical harm may depend especially on the presence of an outcome. Thus, whereas the majority of younger children chose physical harm as worse when an outcome was present, they may have been less likely to choose physical harm when the outcome was absent.

It is worth noting that our Accidental stories still involved an actor (unknowingly) creating a harmful scenario. Recent research demonstrates that children distinguish between unintentional harms resulting from others' false beliefs (e.g., the agent intended to complete an action but did not think the action would result in harm) and unintentional harms resulting from purely mistaken actions (e.g., the agent never intended to complete the action) (Proft \& Rakoczy, 2019), but that the former is more difficult for younger children to understand than the latter (Proft \& Rakoczy, 2019; Proft et al., 2019). Open questions concern how the present results 
would extend to purely mistaken actions. We would predict that the observed condition differences would be the same, if not greater, in the case of "pure" accidents, given the total absence of intentions and the remainder of the outcome. Relatedly, one limitation of the Accidental harm scenarios is the language we used to describe the perpetrator's intentions (i.e., "[the perpetrator] wanted to make [the victim] get a good and fun day"). We used this language to equate the text as closely as possible with that in the other two scenarios (i.e., "get tripped" and "get made fun of"), however this language may have been awkward.

Unlike in Experiment 1, we did not observe an effect of character gender on children's responses to which harm was worse. However, in Experiment 2, we only presented participants with cases involving two girls or two boys. Open questions remain regarding the influence of gender — as well as other aspects of the perpetrator's and victim's identities—on children's comparative reasoning about emotional versus physical harm. For instance, 6-year-old children are more likely to spontaneously protest the moral violations of those in an out-group compared to those in their in-group (Jordan, McAuliffe, \& Warneken, 2014), and children view harm between two members of the same group as violating a relational obligation, but do not judge intergroup harm in the same way (Rhodes \& Chalik, 2013). If evaluations of emotional harm rely especially on considerations of the perpetrator - as we suggest they do - then one possibility is that considerations of emotional harm are particularly sensitive to the perpetrator's identity and relation to the victim.

Last, it is worth noting that children chose emotional harm considerably less often in Experiment 2 than in Experiment 1 (26\% in Experiment 2 versus $48 \%$ in Experiment 1). This difference may result in part from changes we made to the vignettes. In Experiment 2, we removed other children (an audience) from the emotional harm scenario, and we made the causal 
link between the perpetrator and the victim less visibly clear. We also used different language to describe the emotional experience of the perpetrator, using "sad" — a basic emotion—in Experiment 1 and "embarrassed" — a complex emotion —in Experiment 2. These changes may have made the hurtful nature of emotional harm less salient, particularly to younger children. We return to these points in the General Discussion.

\section{General Discussion}

Across two studies, we investigated 5- to 10-year-old children's thinking about emotional harm. Children's reasoning about emotional harm — particularly as compared to physical harmchanged across this age range. With age, children in our samples rated emotional harm as increasingly hurtful, were increasingly likely to choose emotional harm as worse than physical harm, and were increasingly likely to associate emotional harm with longer-lasting impacts.

Children's judgments of emotional harm seemed especially sensitive to perpetrator intentions. In contrast, children's judgments of physical harm were relatively more focused on the outcome of harm. In Experiment 1, children who said physical harm was worse on the first Comparing Harms question tended to choose the mismatched intention-outcome scenario with a physical harm outcome; in contrast, children who chose emotional harm as worse on the first Comparing Harms question were equally likely to choose mismatched intention-outcome stories that featured emotional harm as the intention or the outcome. In Experiment 2, children tended to say emotional harm (vs physical harm) would be more likely to reoccur, but only if the emotional harm was intended. This relative focus on intentions versus outcomes was also reflected in the structure of children's verbal explanations. Children who described the hurt caused by physical harm most often centered their explanations on the victim (on whom the outcome could be visible). Children who described the hurt caused by emotional harm were less 
likely to mention the victim at all; when they did, they often made the victim the grammatical object, focusing instead on the perpetrator, who possessed the intentions to harm.

An important limitation to our analyses of children's verbal explanations is that children only described the hurt caused by the harm they chose as worse. Thus, our results cannot disentangle between the possibilities that differences in children's explanations reflected differences in the reasoning of children who perceived emotional versus physical harms as worse, or differences in the way all children describe emotional versus physical harm. In either case, divergence in the way emotional and physical hurt is described — and that these differences emerge early in life-may hold important consequences. Indeed, variation in children's explanations seemed to reflect more than just differences in natural language. In Experiment 2, our experimental manipulation also influenced the structure of children's explanations: Children more often centered their explanations on the victim when harms were accidental versus incomplete. Future research may also consider how children's attentional focus relates to the content of their explanations. For instance, children's attentional focus on the perpetrator versus victim is likely to parallel children's focus on the action of harming versus the outcome of a harm. Continuing to examine both the structure and content of children's descriptions of harm events is likely to provide rich insight into the factors underlying children's judgments of harm.

Developmental shifts in children's reasoning about intentions may help explain agerelated changes in children's reasoning about emotional harm. As outlined in the introduction, children's understanding of intentions develops over an extended timeline (e.g., Baird \& Astington, 2005; Cushman, 2015; Cushman et al., 2013; Li \& Tomasello, 2018; Margoni \& Surian, 2017; Nobes et al., 2009; Yuill \& Perner, 1988), such that younger children place greater weight on the outcome of harm than do older children and adults. If reasoning about others' 
intentions is important for recognizing the severity of emotional harm, then younger children may struggle to fully comprehend the pain produced by emotional harm. Notably, children rated emotional harm as increasingly hurtful and intentional with age. Future research could consider the causal direction of the relation between children's thinking about the intentionality and severity of emotional harms.

The present findings raise numerous questions about children's thinking about emotional harms. For instance, questions involve whether - and if so, how - the present findings generalize to forms of emotional and physical harms beyond those we included. One limitation of the present studies is that we focus on single incidents of physical and emotional harm. In considering other emotional harms, two relevant considerations are how emotional harms are depicted and described. In Experiment 1, we described the victim's experience using a basic emotion ("sad"), whereas in Experiment 2, we used a complex emotion ("embarrassed"). Using basic versus complex emotion labels (e.g., see Bosacki \& Moore, 2004; Denham, 1998; Lagattuta \& Thompson, 2007) may have contributed to fewer children choosing emotional harm as worse in Experiment 2. More broadly, using basic emotions to describe emotional pain may make the pain more salient, particularly to younger children.

Regarding the depiction of harm, the present findings underscore how the visibility of a harm's outcome may impact children's reasoning. In the scenarios presented, the outcome of emotional harm was experienced internally (i.e., hurt feelings), and the outcome of the physical harm was experienced externally (i.e., a hurt body). A distinction between internal and external harm often maps onto a distinction between emotional and physical harm, but there are certainly exceptions: Physical harm can be experienced internally (e.g., the effects of a disease), and emotional harm can be expressed externally (e.g., via corresponding emotional expressions) or 
made more tangible through other elements of the scenario (e.g., the presence of an audience). In our studies, children were more likely to choose emotional harm as worse than physical harm when an audience was depicted. Relatedly, research suggests the presence of an audience matters particularly for children's reasoning about embarrassment (e.g., Banerjee, 2002; Bennett, 1989; Seidner \& Stipek, 1988). One possibility is that the relative visibility of an outcome impacts children's recognition of emotional and physical injury, but that outcomes are on average less visible in the case of emotional harm.

Other questions concern how children evaluate cases that simultaneously involve emotional and physical harm, or in which the distinction between emotional and physical harm is not dichotomous. Physical harms can result in emotional pain (e.g., an awareness of the perpetrator's intent to inflict harm), and emotional harms can result in physical outcomes (e.g., health outcomes related to stress). Among adults, there is considerable evidence of similarities between the neural responses to physical and social pain (Eisenberger, 2012; Kross, Berman, Mischel, Smith, \& Wager, 2011; Sturgeon \& Zautra, 2016; Zhang, Zhang, \& Kong, 2019), although recent research suggests there may also be important distinctions and interactions between the two (Tsoi, Dungan, Chakroff, \& Young, 2018; for a review, see Ferris, Jetten, Hornsey, \& Bastian, 2019). Children's reasoning about emotional and physical harm may be additive, such that the discrete impacts of each harm are summed together. Relatedly, among adults, the presence of negative intentions to a physical harm can increase perceptions of physical pain (Gray \& Wegner, 2008); thus, one possibility is that intentions add a layer of emotional pain relating to knowing that someone intended you harm (Ames \& Fiske, 2013; Bilz \& Darley, 2004; Decety, Michalska, \& Akitsuki, 2008; Gray \& Wegner, 2008). 
Alternatively, experiences of emotional and physical harm may interact or be treated more like one kind of harm in isolation (see Zhang et al., 2019 for relevant discussion with respect to adults). Or, certain combinations of emotional and physical harm may be evaluated as worse than others. In the mismatched intention-outcome stories in Experiment 1, more children chose the emotional intention/physical outcome story as worse than the physical intention/emotional outcome story. The specific combination of a physical harm outcome and emotional harm intentions may combine the worst elements of each kind of harm, thus seeming worse than the opposite combination. A complementary possibility is that emotional pain that arises from a harm for which the outcome is more visible (e.g., physical harm, theft) may be easier to recognize - particularly for younger children.

In considering the above questions, a critical consideration is whether and how children's reasoning about emotional and physical harm varies across different cultural settings and demographic groups. The present findings are limited in that the samples tested are from a relatively homogeneous region of the United States. Given the role of culture in shaping morality (e.g., Miller \& Bland, 2014; Miller, Wice, \& Goyal, 2019; Shweder, Mahapatra, \& Miller, 1987; Wainryb \& Recchia, 2014), it remains unknown whether and how the present findings generalize across cultural settings, and to what extent the developmental trajectory of reasoning about emotional harm may vary across contexts. For example, relative emphasis on empathy and other people's feelings may shape the development of children's thinking about emotional harms.

Beyond its contributions to an understanding of children's moral reasoning, a better understanding of emotional harm holds implications for legal theory and the psychology of law. Both criminal and civil law center on the redress of harm, and both distinguish between emotional and physical harm. Whereas physical injuries routinely give rise to criminal charges or 
civil suits, claims based on emotional injuries are considerably more difficult to pursue. Indeed, many legal doctrines make it difficult or even impossible to recover for an emotional injury unless it is accompanied by actual or imminent physical injury (Davies, 1992; Rabin, 2009).

The legal literature has suggested a number of possible reasons for this dichotomy, including that the law does not (or should not) recognize an interest in "peace of mind" (Magruder, 1936), and problems of proof, related to worries that emotional harm is difficult to verify and judge (Rabin, 2009). Another possibility is that these doctrinal differences reflect intuitive psychological reasoning about harm. Understanding the extent to which this is the case can inform legal theories of harm and help shape legal institutions and policies to maximize perceptions of legitimacy and fairness (see Bregant, Shaw, \& Kinzler, 2016). The present results - demonstrating that a recognition of the hurt caused by emotional harm has a relatively protracted developmental trajectory — suggest the distinction made in the law may have its roots in intuitive thinking about emotional and physical harm.

Finally, an examination of emotional harm may inform interventions relating to children's own experiences with harm. In recent years, there has been an increasing focus on understanding and remedying bullying in schools. In the United States, more than one-fifth of students report being bullied (National Center for Education Statistics, 2017), making it a widespread experience that is likely to have vast consequences for development. Bullying can take multiple forms, but it is most frequently verbal and social in nature (National Center for Education Statistics and Bureau of Justice Statistics). Our results demonstrate that children's reasoning about emotional versus physical harm differ, and call into question whether the same interventions will work equally well for targeting these two kinds of harm. Future research and interventions could examine the efficacy of focusing on the intentions of emotional harms, 
emphasizing the lasting impacts of emotional pain, or of helping children to connect instances of emotional harm with tangible or visible outcomes. Likewise, interventions may benefit from considering children's potentially differential attention to the perpetrator, victim, and bystanders involved. Children may focus more on the perpetrator than the victim in cases of emotional harm. If this is the case, it may be harder for children to identify with the experience of the victim in cases of emotional harm (particularly when the victim's experience is especially intangible; e.g., cyberbullying).

The present work highlights the importance of considering children's reasoning about emotional harm as separable from their reasoning about physical harm. We demonstrate that a recognition of the hurt caused by emotional harm — which can be long-lasting — strengthens with age, and is especially sensitive to thinking about a perpetrator's intentions. These findings underscore the importance of the continued empirical investigation of emotional harm and offer insights into moral development, law and psychology, and emotional harm-related interventions. 


\section{References}

Ames, D. L., \& Fiske, S. T. (2013). Intentional Harms Are Worse, Even When They're Not. Psychological Science, 24(9), 1755-1762. https://doi.org/10.1177/0956797613480507

Atance, C. (2015). Young children's thinking about the future. Child Development Perspectives, 9(3), 178-182. https://doi.org/ 10.1111/cdep.12128

Baird, J. A., \& Astington, J. W. (2005). The Development of the Intention Concept: From the Observable World to the Unobservable Mind. In R. R. Hassin, J. S. Uleman, \& J. A. Bargh (Eds.), Oxford series in social cognition and social neuroscience. The new unconscious (pp. 256-276). Oxford University Press. https://doi.org/10.1093/acprof

Ball, C. L., Smetana, J. G., \& Sturge-Apple, M. L. (2017). Following my head and my heart: Integrating preschoolers' empathy, theory of mind, and moral judgments. Child Development, 88(2), 597-611. https://doi.org/10.1111/cdev.12605

Banerjee, R. (2002). Children's understanding of self-presentational behavior: Links with mental-state reasoning and the attribution of embarrassment. Merrill-Palmer Quarterly, 48(4), 378-404. https://doi.org/10.1353/mpq.2002.0015

Bennett, M. (1989). Children's self-attribution of embarrassment. British Journal of Developmental Psychology, 7, 207-217. https://doi.org/10.1111/j.2044835X.1989.tb00801.X

Bilz, K., \& Darley, J. M. (2004). What's Wrong with Harmless Theories of Punishment. Chicago-Kent Law Review, 79, 1215-1252.

Björkqvist, K. (1994). Sex differences in physical, verbal and indirect agressions: a review of recent research. Sex Roles, 30(3/4), 177-188. https://doi.org/360-0025/94/02000177507.000 
Bloom, P. (2004). Descartes’Baby. Cambridge, Massachusetts: Basic Books.

Bosacki, S. L., \& Moore, C. (2004). Preschoolers' understanding of simple and complex emotions: Links with gender and language. Sex Roles, 50(9-10), 659-675. https://doi.org/10.1023/b:sers.0000027568.26966.27

Bregant, J., Shaw, A., \& Kinzler, K. D. (2016). Intuitive Jurisprudence: Early Reasoninging about the Functions of Punishment. Journal of Empirical Legal Studies, 13(4), 693-717. https://doi.org/10.1017/CBO9781107415324.004

Buss, A. H., Iscoe, I., \& Buss, E. H. (1979). The Development of Embarrassment. The Journal of Psychology, 103, 227-230.

Chen, Z., Williams, K. D., Fitness, J., \& Newton, N. C. (2008). When hurt will not heal: Exploring the capacity to relive social and physical pain. Psychological Science, 19(8), 789-795. https://doi.org/10.1111/j.1467-9280.2008.02158.x

Chernyak, N., \& Sobel, D. M. (2016). "But he didn't mean to do it": Preschoolers correct punishments imposed on accidental transgressors. Cognitive Development, 39, 13-20. https://doi.org/10.1016/j.cogdev.2016.03.002

Chobhthaigh, S. N., \& Wilson, C. (2015). Children's understanding of embarrassment: Integrating mental time travel and mental state information. British Journal of Developmental Psychology, 33(3), 324-339. https://doi.org/10.1111/bjdp.12094

Colonnesi, C., Engelhard, I. M., \& Bögels, S. M. (2010). Development in children's attribution of embarrassment and the relationship with theory of mind and shyness. Cognition and Emotion, 24(3), 514-521. https://doi.org/10.1080/02699930902847151

Crick, N. R., Bigbee, M. A., \& Howes, C. (1996). Gender Differences in Children's Normative Beliefs about Aggression: How Do I Hurt Thee? Let Me Count the Ways. Child 
Development, 67(3), 1003-1014. https://doi.org/10.2307/1131876

Crick, N. R., \& Werner, N. E. (1998). Response Decision Processes in Relational and Overt Aggression. Child Development, 69(6), 1630-1639. https://doi.org/10.1111/j.14678624.2010.01521.x

Cushman, F. (2015). Deconstructing intent to reconstruct morality. Current Opinion in Psychology, 6, 97-103. https://doi.org/10.1016/j.copsyc.2015.06.003

Cushman, F., Sheketoff, R., Wharton, S., \& Carey, S. (2013). The development of intent-based moral judgment. Cognition, 127(1), 6-21. https://doi.org/10.1016/j.cognition.2012.11.008

Davies, J. A. (1992). Direct Actions for Emotional Harm: Is Compromise Possible? Washington Law Review, 1(67), 1-53.

Decety, J., Michalska, K. J., \& Akitsuki, Y. (2008). Who caused the pain? An fMRI investigation of empathy and intentionality in children. Neuropsychologia, 46(11), 26072614. https://doi.org/10.1016/j.neuropsychologia.2008.05.026

Denham, S. A. (1998). Emotional Development in Young Children. New York, New York: The Guilford Press.

Eisenberger, N. I. (2012). The neural bases of social pain: Evidence for shared representations with physical pain. Psychosomatic Medicine, 74(2), 126-135. https://doi.org/10.1097/PSY.0b013e3182464dd1

Fagot, B. I., \& Hagan, R. (1991). Observations of Parent Reactions to Sex-Stereotyped Behaviors : Age and Sex Effects. Child Development, 62(3), 617-628. https://doi.org/https://doi.org/10.1037/0012-1649.22.1.103

Ferris, L. J., Jetten, J., Hornsey, M. J., \& Bastian, B. (2019). Feeling Hurt: Revisiting the Relationship Between Social and Physical Pain. Review of General Psychology, 23(3), 320- 
335. https://doi.org/10.1177/1089268019857936

Giles, J. W., \& Heyman, G. D. (2005). Young children's beliefs about the relationship between gender and aggressive behavior. Child Development, 76(1), 107-121. https://doi.org/10.1111/j.1467-8624.2005.00833.x

Goldstein, S. E., Tisak, M. S., \& Boxer, P. (2002). Preschoolers' Normative and Prescriptive Judgements about Relational and Overt Aggression. Early Education and Development, 13(1), 41-58. https://doi.org/10.1207/s15566935eed1301

Gray, K., \& Wegner, D. M. (2008). The sting of intentional pain. Psychological Science, 19(12), 1260-1262. https://doi.org/10.1111/j.1467-9280.2008.02208.x

Hamlin, J. K. (2013). Failed attempts to help and harm: Intention versus outcome in preverbal infants' social evaluations. Cognition, 128(3), 451-474. https://doi.org/10.1016/j.cognition.2013.04.004

Hamlin, J. K., Wynn, K., \& Bloom, P. (2007). Social evaluation by preverbal infants. Nature, 450(7169), 557-559. https://doi.org/10.1038/nature06288

Heck, I. A., \& Kinzler, K. (2020, November 13). Emotional Harm. Retrieved from osf.io/64vha Helwig, C. C., Hildebrandt, C., \& Turiel, E. (1995). Children's Judgments about Psychological Harm in Social Context. Child Development, 66, 1680-1693. https://doi.org/10.2307/1131903

Helwig, C. C., Zelazo, P. D., \& Wilson, M. (2001). Children's judgments of psychological harm in normal and noncanonical situations. Child Development, 72(1), 66-81. https://doi.org/10.1111/1467-8624.00266

Imamoglu, O. (1975). Children's Awareness and Usage of Intention Cues. Child Development, 46, 39-45. https://doi.org/https://doi.org/10.1037/0033-2909.85.1.76 
Jordan, J. J., McAuliffe, K., \& Warneken, F. (2014). Development of in-group favoritism in children's third-party punishment of selfishness. Proceedings of the National Academy of Sciences, 111(35), 12710-12715. https://doi.org/10.1073/pnas.1402280111

Killen, M., Lynn Mulvey, K., Richardson, C., Jampol, N., \& Woodward, A. (2011). The accidental transgressor: Morally-relevant theory of mind. Cognition, 119(2), 197-215. https://doi.org/10.1016/j.cognition.2011.01.006

Kim, M. (1996). Pragmatic determinants of syntactic subject in English. Journal of Pragmatics, 25(6), 839-854. https://doi.org/10.1016/0378-2166(95)00018-6

Kohlberg, L. (1969). Stage and sequence: The cognitive-developmental approach to socialization. In D. A. Goslin (Ed.), Handbook of socialization theory and research. (pp. 151-235). New York: Academic Press.

Kohlberg, L., \& Kramer, R. (1969). Continuities and discontinuities in childhood and adult moral development. Human Development, 12(2), 93-120. https://doi.org/10.1159/000270857

Kross, E., Berman, M. G., Mischel, W., Smith, E. E., \& Wager, T. D. (2011). Social rejection shares somatosensory representations with physical pain. Proceedings of the National Academy of Sciences of the United States of America, 108(15), 6270-6275. https://doi.org/10.1073/pnas.1102693108

Lagattuta, K. H. (2014). Linking past, present, and future: Children's ability to connect mental states and emotions across time. Child Development Perspectives, 8(2), 90-95. https://doi.org/10.1111/cdep.12065

Lagattuta, K. H., \& Sayfan, L. (2013). Not all past events are equal: Biased attention and emerging heuristics in children's past-to-future forecasting. Child Development, 84(6), 
2094-2111. https://doi.org/10.1111/cdev.12082

Lagattuta, K. H., Tashjian, S. M., \& Kramer, H. J. (2018). Does the past shape anticipation for the future? Contributions of age and executive function to advanced theory of mind. Zeitschrift Fur Psychologie / Journal of Psychology, 226(2), 122-133. https://doi.org/10.1027/2151-2604/a000328

Lagattuta, K. H., \& Thompson, R. A. (2007). The development of self-conscious emotions: Cognitive processes and social influences. In J.L. Tracy, R.W. Robbins, \& J.P. Tangney (Eds.), The Self-Conscious Emotions: Theory and Research (pp. 91-113). New York, New York: Guilford Press.

Lagattuta, K. H., \& Wellman, H. M. (2001). Thinking about the past: Early knowledge about links between prior experience, thinking, and emotion. Child Development, 72(1), 82-102. https://doi.org/10.1111/1467-8624.00267

Lempert, H., \& MacWhinney, B. (1984). Topic as Starting Point for Syntax. Monographs of the Society for Research in Child Development, 49(5), 1-73.

Li, J., \& Tomasello, M. (2018). The development of intention-based sociomoral judgment and distribution behavior from a third-party stance. Journal of Experimental Child Psychology, 167, 78-92. https://doi.org/10.1016/j.jecp.2017.09.021

Margoni, F., \& Surian, L. (2017). Children's intention-based moral judgments of helping agents. Cognitive Development, 41, 46-64. https://doi.org/10.1016/j.cogdev.2016.12.001 McCormack, T. (2015). The Development of Temporal Cognition. Handbook of Child Psychology and Developmental Science, March, 1-47. https://doi.org/ 10.1002/9781118963418.childpsy215

McCormack, T., Feeney, A., \& Beck, S.R. (2020). Regret and Decision-Making: A 
Developmental Perpsective. Current Directions in Psychological Science, 29(4), 346-350. https://doi.org/10.1177/0963721420917688

McCormack, T., \& Hoerl, C. (2017). The Development of Temporal Concepts: Learning to Locate Events in Time. Timing and Time Perception, 5(3-4), 297-327, https://doi.org/10.1163/22134468-00002094

Miller, J. G., \& Bland, C. G. (2014). A Cultural Psychology Perspective on Moral Development. In M. Killen \& J. G. Smetana (Eds.), Handbook of Moral Development, Second Edition (pp. 299-314). New York, New York. https://doi.org/10.4324/9780203581957

Miller, J. G., Wice, M., \& Goyal, N. (2019). Culture, Parenting Practices, and Moral Development. In D. J. Laible, G. Carlo, \& L. M. Padilla Walker (Eds.), The Oxford Handbook of Parenting and Moral Development (pp. 147-158). New York, New York: Oxford University Press.

Murray-Close, D., Crick, N. R., \& Galotti, K. M. (2006). Children's Moral Reasoning Regarding Physical and Relational Aggression. Social Development, 15(3), 345-369. https://doi.org/10.12775/FT.2017.020

Myachykov, A., Garrod, S., \& Scheepers, C. (2018). Attention and Memory Play Different Roles in Syntactic Choice During Sentence Production. Discourse Processes, 55(2), 218-229. https://doi.org/10.1080/0163853X.2017.1330044

Myachykov, A., Tomlin, R. S., \& Posner, M. I. (2005). Attention and empirical studies of grammar. The Linguistic Review, 22(2005), 347-364. https://doi.org/10.1515/tlir.2005.22.24.347

Nobes, G., Panagiotaki, G., \& Pawson, C. (2009). The influence of negligence, intention, and outcome on children's moral judgments. Journal of Experimental Child Psychology, 104(4), 
382-397. https://doi.org/10.1016/j.jecp.2009.08.001

Piaget, J. (1997). The Moral Judgment of the Child. New York, NY: Free Press Paperbacks.

(Original work published 1932).

Pons, F., Harris, P. L., \& de Rosnay, M. (2004). Emotion Comprehension between 3 and 11 years: Developmental periods and hierarchical organization. European Journal of Developmental Psychology, 1(2), 127-152. https://doi.org/https://doi.org/10.1080/17405620344000022

Proft, M., \& Rakoczy, H. (2019). The ontogeny of intent-based normative judgments. Developmental Science, 22(2), 1-16. https://doi.org/10.1111/desc.12728

Proft, M., Schünemann, B., \& Rakoczy, H. (2019). Children's understanding of the aspectuality of intentions. Journal of Experimental Child Psychology, 181, 17-33. https://doi.org/10.1016/j.jecp.2018.12.001

Rabin, R. L. (2009). Emotional Distress in Tort Law: Themes of Constraint. Wake Forest L. Rev., 44, 1197.

Rhodes, M., \& Chalik, L. (2013). Social Categories as Markers of Intrinsic Interpersonal Obligations. Psychological Science, 24(6), 999-1006. https://doi.org/10.1177/0956797612466267

Riedl, K., Jensen, K., Call, J., \& Tomasello, M. (2015). Restorative Justice in Children. Current Biology, 25(13), 1731-1735. https://doi.org/10.1016/j.cub.2015.05.014

Seidner, L. B., \& Stipek, D. J. (1988). A Developmental Analysis of Elementary School-Aged Children's Concepts of Pride and Embarrassment. Child Development, 59(2), 367-377. https://doi.org/10.2307/1130316

Shweder, R. A., Mahapatra, M., \& Miller, J. G. (1987). Culture and Moral Development. In J. 
Kagan \& S. Lamb (Eds.), The Emergence of Morality in Young Children (pp. 292-317).

Chicago: University of Chicago Press.

https://doi.org/10.1093/oso/9780190679743.003.0010

Singer, P. (1981). The Expanding Cirlce: Ethics and Sociobiology. New York, New York: Farrar Straus \& Giroux.

Smetana, J. G. (2013). Young Children's Moral and Social-Conventional Understanding. In M.

R. Banaji \& S. A. Gelman (Eds.), Navigating the social world: What infants, children, and other species can teach us (pp. 352-355). New York: Oxford University Press.

Smetana, J. G., Campione-Barr, N., \& Yell, N. (2003). Children's moral and affective judgments regarding provocation and retaliation. Merrill-Palmer Quarterly, 49(2), 209-236. https://doi.org/10.1353/mpq.2003.0010

Smetana, J. G., Jambon, M., \& Ball, C. (2014). The Social Domain Approach to Children's Moral and Social Judgments. In M. Killen \& J. G. Smetana (Eds.), Handbook of Moral Development, 2nd Edition (pp. 23-45). New York: Psychology Press.

Sturgeon, J. A., \& Zautra, A. J. (2016). Social pain and physical pain: shared paths to resilence. Pain Management, 6(1), 63-74. https://doi.org/10.2217/pmt.15.56

Tannenbaum, P. H., \& Williams, F. (1968). Generation of Active and Passive Sentences as a Function of Subject or Object Focus. Journal of Verbal Learning and Verbal Behavior, 7, 246-250.

Tisak, M. S., Tisak, J., \& Goldstein, S. E. (2001). How Do Young Children Misbehave in the Grocery Store and in the School? The Preschoolers' Perspective. Early Education \& Development, 12(4), 577-592. https://doi.org/10.1207/s15566935eed1204

Tillman, K.A., Marghetis, T., Barner, D., \& Srinivasan, M. (2017). Today is tomorrow’s 
yesterday: Children's acquisition of deictic time words. Cognitive Psychology, 92, 87-100. https://doi.org/10.1016/j.cog.psych.2016.10.003

Tomlin, R.S. (1983). On the Interaction of Syntactic Subject, Thematic Information, and Agent in English. Journal of Pragmatics, 7(4), 411-432. https://doi.org/10.1016/03782166(83)90026-7

Tsoi, L., Dungan, J. A., Chakroff, A., \& Young, L. L. (2018). Neural substrates for moral judgments of psychological versus physical harm. Social Cognitive and Affective Neuroscience, 13(5), 460-470. https://doi.org/10.1093/scan/nsy029

Vaish, A., Carpenter, M., \& Tomasello, M. (2009). Sympathy through affective perspective taking and its relation to prosocial behavior in toddlers. Developmental Psychology, 45(2), 534-543. https://doi.org/10.1037/a0014322

Vaish, A., Carpenter, M., \& Tomasello, M. (2010). Young Children Selectively Avoid Helping People With Harmful Intentions. Child Development, 81(6), 1661-1669. https://doi.org/10.1111/j.1467-8624.2010.01500.x

Vaish, A., Missana, M., \& Tomasello, M. (2011). Three-year-old children intervene in thirdparty moral transgressions. The British Journal of Developmental Psychology, 29(Pt 1), 124-130. https://doi.org/10.1348/026151010X532888

Van de Vondervoort, J. W., \& Hamlin, J. K. (2017). Preschoolers' social and moral judgments of third-party helpers and hinderers align with infants' social evaluations. Journal of Experimental Child Psychology, 164, 136-151. https://doi.org/10.1016/j.jecp.2017.07.004

Van de Vondervoort, J. W., \& Hamlin, J. K. (2018). Preschoolers focus on others' intentions when forming sociomoral judgments. Frontiers in Psychology, 9(OCT), 1-17. https://doi.org/10.3389/fpsyg.2018.01851 
Wainryb, C., \& Recchia, H. (2014). Moral Lives Across Cultures: Heterogeneity and Conflict. In M. Killen \& J. G. Smetana (Eds.), Handbook of Moral Development, Second Edition (pp. 259-278). New York, New York: Psychology Press.

https://doi.org/10.4324/9780203581957

Wellman, H. M., Cross, D., \& Watson, J. (2001). Meta-analysis of theory-of-mind development: the truth about false belief. Child Development, 72(3), 655-684. https://doi.org/10.1111/1467-8624.00304

Woo, B. M., Steckler, C. M., Le, D. T., \& Hamlin, J. K. (2017). Social evaluation of intentional, truly accidental, and negligently accidental helpers and harmers by 10 -month-old infants. Cognition, 168, 154-163. https://doi.org/10.1016/j.cognition.2017.06.029

Woodward, A. (2013). Infant Foundations of Intentional Understanding. Navigating the Social World. https://doi.org/10.1093/acprof:oso/9780199890712.003.0015

Yau, J., \& Smetana, J. G. (2003). Conceptions of Moral, Social-Conventional, and Personal Events Among Chinese Preschoolers in Hong Kong. Child Development, 74(3), 647-658. https://doi.org/10.1111/1467-8624.00560

Yoo, H. N., \& Smetana, J. G. (2019). Children’s moral judgments about psychological harm: Links among harm salience, victims' vulnerability, and child sympathy. Journal of Experimental Child Psychology, 188, 104655. https://doi.org/10.1016/j.jecp.2019.06.008

Yudkin, D. A., Van Bavel, J. J., \& Rhodes, M. (2019). Young Children Police Group Members at Personal Cost. Journal of Experimental Psychology: General, 149(1), 182-191. https://doi.org/10.1002/yea.1312

Yuill, N., \& Perner, J. (1988). Intentionality and knowledge in children's judgments of actor's responsibility and recipient's emotional reaction. Developmental Psychology, 24(3), 358- 
365. https://doi.org/10.1037/0012-1649.24.3.358

Zelazo, P. D., Helwig, C. C., \& Lau, A. (1996). Intention, Act, and Outcome in Behavioral Prediction and Moral Judgment. Child Development, 67(5), 2478-2492. https://doi.org/https://www.jstor.org/stable/1131635

Zhang, M., Zhang, Y., \& Kong, Y. (2019). Interaction between social pain and physical pain. Brain Science Advances, 5(4), 265-273. https://doi.org/10.26599/bsa.2019.9050023 